\title{
UNILATERAL RETINAL VASCULAR MALFORMATION IN HEREDITARY HEMORRHAGIC TELANGIECTASIA
}

\author{
S. Ananth Bhandary ${ }^{1}$, Hemalatha B. C², Sathyendranath B. Shetty ${ }^{3}$
}

\section{HOW TO CITE THIS ARTICLE:}

S. Ananth Bhandary, Hemalatha B. C, Sathyendranath B. Shetty. "Unilateral Retinal Vascular Malformation in Hereditary Hemorrhagic Telangiectasia". Journal of Evolution of Medical and Dental Sciences 2014; Vol. 3, Issue 31, July 31; Page: 8637-8641, DOI: 10.14260/jemds/2014/3099

\begin{abstract}
Hereditary hemorrhagic telangeiectasia (HHT) is an autosomal dominant genetic disorder that leads to vascular malformations. It was first recognized in the 19th century as a familial disorder with abnormal vascular structures causing bleeding from the nose and gastrointestinal tract. HHT is characterized by telangiectatic lesions of the nose, lips, lungs, brain, and spinal cord. The reported incidence in Europe and Japan is between 1:5000 and 1:8000; but is widely variable in other regions. It is seen more frequently in whites. Ocular involvement has been reported in patients with HHT. Although conjunctival telangiectasia is the most common manifestation, rarely intraocular vascular lesions such as retinal telangiectasia and arteriovenous malformations in the retina, are seen. We describe a patient with HHT who had an abnormal unilateral retinal vascular abnormality along with tortuous conjunctival vasculature in the other eye, which has not been reported till date.
\end{abstract}

KEYWORDS: Hereditary hemorrhagic telangiectasia, Retinal vascular abnormality, Mucosal telengectasia.

INTRODUCTION: Hereditary hemorrhagic telangeiectasia is an autosomal dominant genetic disorder that leads to vascular malformations. It was first recognized in the 19th century as a familial disorder with abnormal vascular structures causing bleeding from the nose and gastrointestinal tract. HHT is characterized by telangiectatic lesions of the nose, lips and visceral organs [lungs, brain and spinal cord].[1] Reported incidence in Europe and Japan is between 1:5000 and 1:8000; but widely variable in other regions. More frequently occurs in whites.

CASE HISTORY: A 20years old male, a known case of hereditary haemorrhagic telangiectasia, suffering from recurrent skin lesions and infections was on treatment for the last 12years. He had received systemic antibiotics and had undergone a left leg amputation, for the same. He gave history of recurrent epistaxis for the last seven years which had resolved after taking systemic hormonal therapy. Mucocutaneous examination revealed erythematous telangectatic blanchable lesions noted over the tongue and also in hard palate. (Figure 1a).

Erythematous patchy reticulate patterned punctuate telangectatic lesions present on the lateral aspect of the feet and on the left shoulder extending on to the medial side of left arm and forearm, palms and dorsum of the hands (Figure 1b, c).

Ocular examination revealed that the corrected distance visual acuity was $20 / 20$ in both eyes. Anterior segment and Slit lamp examination of the right eye was normal while there were several patches of a cork screw like tortuous vessel over the left eye bulbar conjunctiva (Figure 2a). Fundus examination showed normal retinal vasculature in the left eye (Figure 2b) while the right eye revealed obvious vascular abnormalities (Figure 3a) along the inferior arcade. 
Both arteriole and venule appeared more dilated and tortuous compared to superior branches. Surrounding the foveal avascular zone, an abnormality of the vascular network was noted. On fundus fluorescein angiography (Figure. 3 b, c, d), there was an early filling of the dye in the inferior retinal blood vessels and the marked dilatation and tortuosity of retinal vasculature was clearly made out. These ectactic vessels were distributed from the peri-papillary area to the periphery. However there was no dye leakage or staining in the late phase. No abnormalities were detected on ICG angiography.

DISCUSSION: Earlier reports indicate that the ocular involvement in hereditary hemorrhagic telangectasia (HHT) varies between $45 \%$ and $65 \%$, of which the most common lesion involves the conjunctiva.[1] Intraocular involvement in hereditary hemorrhagic telangiectasia is relatively rare, it has been estimated that its incidence would be less than 1\%, when based on 1500 reported cases of HHT.[2]

Since Francois first described intraocular involvement in 1938, reports of fundus abnormalities were predominantly vascular lesions of retina or optic disc. ${ }^{1-4]}$ More specific lesions are dilated and tortuous veins and tortuous arterioles of the retina.[1] Retinal telangiectasia, localized arteriovenous malformation, vitreous hemorrhage, and newly formed vessels in the retina or on the disc have also been reported.[1,3,4]

The prevalence of retinal telangiectasia is reported to be lower than $1 / 75(<1.3 \%)$. ${ }^{10]}$ In our patient, arteriovenous dilatation was confined to one eye only and also more obvious in inferior branches. The enlarged and tortuous retinal vessels were not associated with any dye leakage on FFA. These abnormal retinal vessels were seen from the peripapillary area to the periphery along with few abnormalities in the perifoveal capillary network in the right eye.

Similar to our case, Brant et al[1] described a patient with a network of telangiectatic vessels in the retina that did not show any leakage on FFA. It seems that these intraocular vascular anomalies in HHT have an intact barrier function and do not leak. However, the surrounding abnormal retinal vessels have pigmentary alterations [9] and this implies that the ectactic retinal vessel induces degenerative change of the retinal pigment epithelium (RPE). The possibility of micro-exudation from these ectactic vessels cannot be ruled out.

Choroidal involvement in HHT has been reported by D-C Tsai et al,[5] in the form of choroidal telangiectasia with decreased vision due to serous retinal pigment epithelial detachment confirmed in the ICG angiography. The other ocular manifestation reported are, bloody tears,[7] bulbar conjunctival telangiectasia,[8] choroidal manifestation like unilateral intraoperative choroidal hemorrhage during phacoemulsification.[6]

The most common and early systemic manifestation is epistaxis and often occurs in childhood, which was seen in our patient too. Pulmonary Arterio-Venous malformations generally become apparent after puberty, although they may be present during childhood, while mucocutaneous and gastrointestinal telangiectasias develop progressively with age. Hence it is a must to have periodic follow-up for all HHT patients.

In conclusion, the retinal vascular alteration represents a rare intraocular manifestation of HHT and can occasionally be the presenting finding. Early diagnosis of this rare disease helps to prevent future systemic complications. 


\section{REFERENCES:}

1. Brant AM, Schachat AP, White RI. Ocular manifestations in hereditary hemorrhagic telangiectasia (Rendu-Osler-Weber disease). Am J Ophthalmol 1989; 107: 642-646.

2. Davis DG, Smith JL. Retinal involvement in hereditary hemorrhagic telangiectasia. Arch Ophthalmol 1971; 85: 618-623.

3. Landau J, Nelken E, Davis E. Hereditary hemorrhagic telangiectasia with retinal and conjuncitval lesions. Lancet 1956; 271: 230-231

4. Forker E, Bean W. Retinal arteriovenous aneurysm in hereditary hemorrhagic telangiectasia. Arch Intern Med 1963; 111: 778-783.

5. D-C Tsai, A-G Wang, A-F Lee, W-M Hsu, J-H Liu and M-Y Yen. Choroidal telangiectasia in a patient with hereditary hemorrhagic telangiectasia. Eye (Lond) 2002 Jan; 16 (1), 92-4.

6. Szaflik J, Kamińska A, Zaraś M. Intraoperative choroidal hemorrhage in patient with OslerRendu syndrome. Klin Oczna. 2005; 107 (1-3):133-6.

7. Pizzamiglio-Martín C, Gil-Cazorla R, Guzmán-Glázquez J.Ophthalmologic diagnosis of hereditary hemorrhagic telangiectasia or Rendu-Osler-Weber disease. Arch Soc Esp Oftalmol. 2008 Jun; 83 (6): 381-4.

8. A Knox and D G Frazer, Ophthalmic presentation of hereditary haemorrhagic telangiectasia. Eye (Lond). 2004 Sep; 18 (9): 947-949.

9. Rinaldi M, Buscarini E, Danesino C, Chiosi F, De Benedictis A, Porcellini A, Costagliola C. Ocular manifestations in hereditary hemorrhagic telangiectasia (Rendu-Osler-Weber disease): a caseseries. Ophthalmic Genet. 2011 Mar; 32 (1): 12-7.

10. Geisthoff UW, Hille K, Ruprecht KW, Verse T, Plinkert PK. Prevalence of ocular manifestations in hereditary hemorrhagic telangiectasia. Graefes Arch Clin Exp Ophthalmol. 2007 Aug; 245 (8): 1141-4.

Figure 1a: Erythematous telangiectatic blanchable lesions noted over the tongue and also on the hard palate. Erythematous patchy reticulate patterned punctate telangiectatic lesions over the leg (1b) and palms (1c).

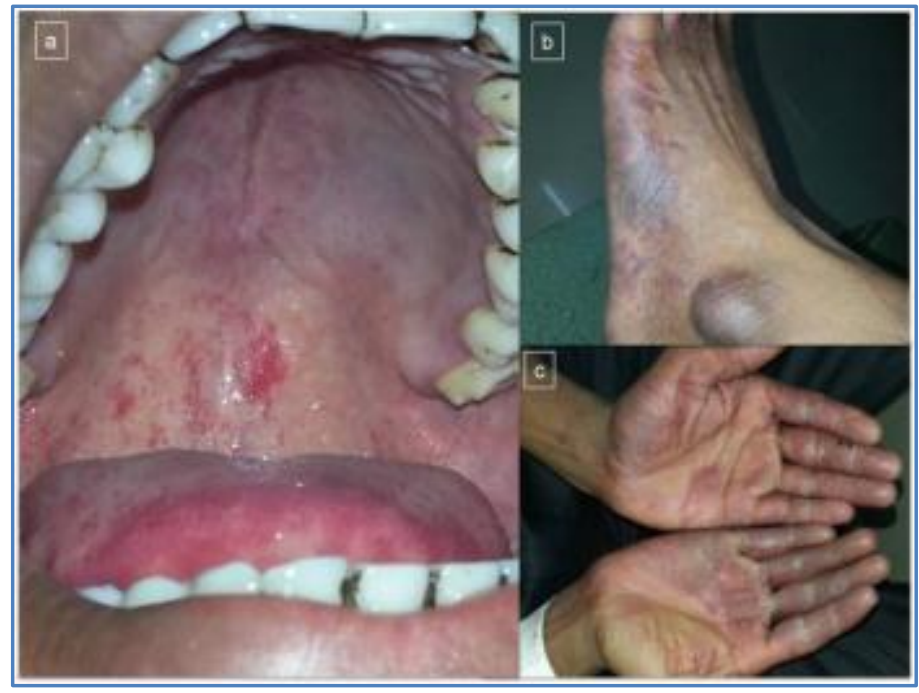

Fig. 1a, 1b, 1c 


\section{CASE REPORT}

Figure 2a: Left eye- Tortuous bulbar conjunctival blood vessels, 2b: Normal retinal vasculature.

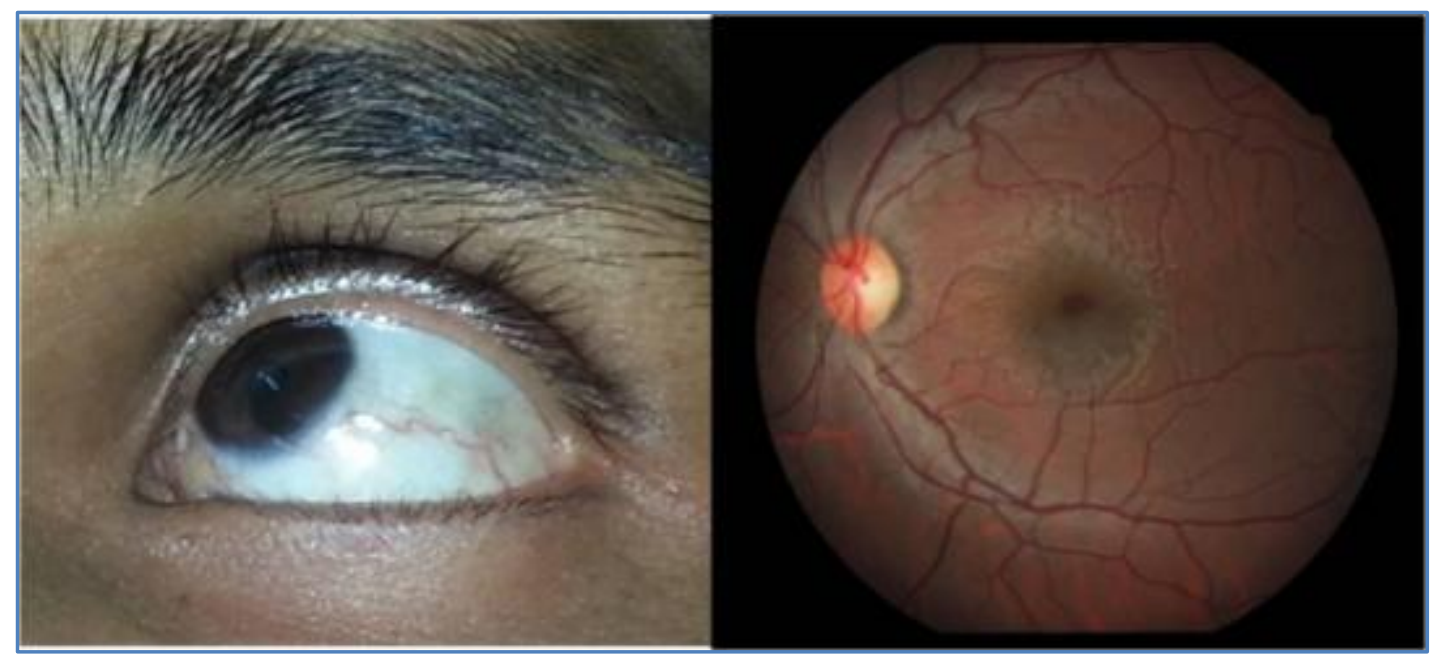

Fig. 2a, 2b

Figure 3: (Right eye)- Retinal vasculature showing abnormal tortuous blood vessels along the inferior arcade (3a). Early (3b), mid (3c) and late phase (3d) Fundus Fluosrescein angiogram images showing early filling of inferior branches, without any dye leakage in late phase.

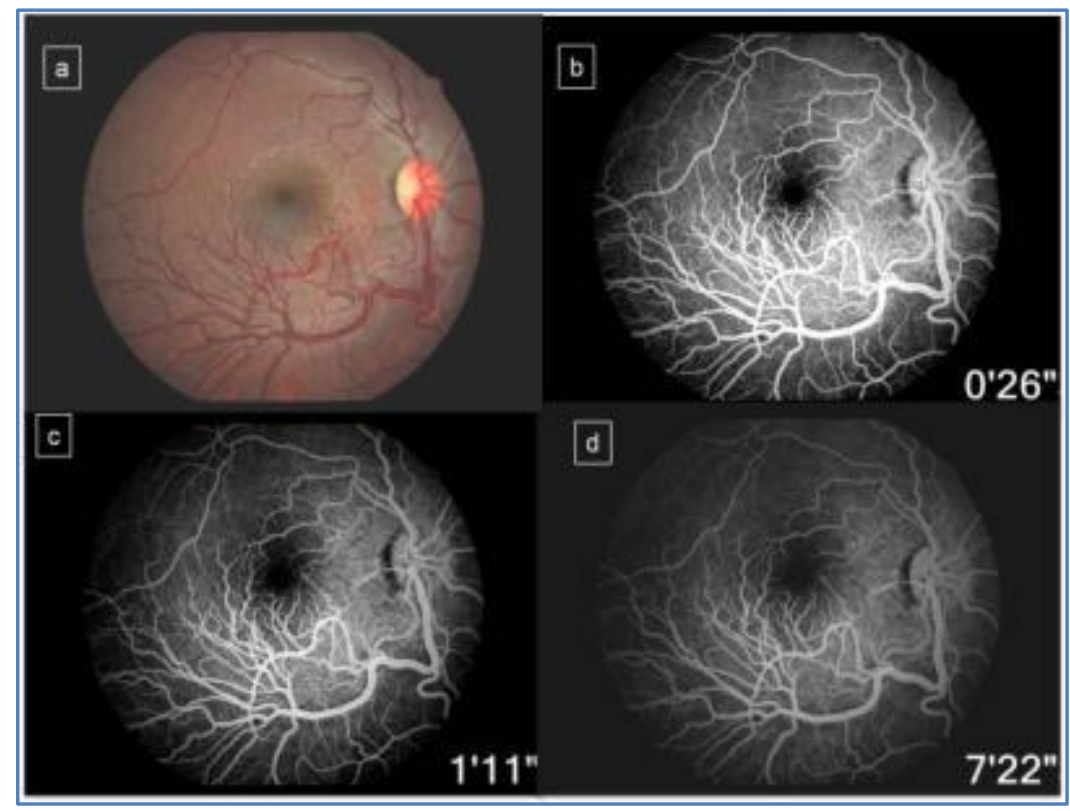

Fig. 3a, 3b, 3c, 3d 


\section{CASE REPORT}

\section{AUTHORS:}

1. S. Ananth Bhandary

2. Hemalatha B. C.

3. Sathyendranath B. Shetty

\section{PARTICULARS OF CONTRIBUTORS:}

1. Associate Professor, Department of Ophthalmology, M.S. Ramaiah Medical Teaching Hospital, Bangalore.

2. Assistant Professor, Department of Ophthalmology, Vitreo-retina Section, M.S. Ramaiah Medical Teaching Hospital, Bangalore.

3. Associate Professor, Department of Ophthalmology, M.S. Ramaiah Medical Teaching Hospital, Bangalore.

\section{NAME ADDRESS EMAIL ID OF THE} CORRESPONDING AUTHOR:

Dr. Hemalatha B. C, Assistant Professor, Department of Ophthalmology, M.S. Ramaiah Medical College, Bangalore.

Email: subhema@gmail.com

Date of Submission: 15/07/2014. Date of Peer Review: 16/07/2014. Date of Acceptance: 24/07/2014. Date of Publishing: 31/07/2014. 